\title{
Sexualidade e saúde mental: Construindo sentidos com pessoas usuárias de um CAPS
}

Vitor Corrêa Detomini. Prefeitura da Estância Turística de Pereira Barreto.

Emerson Fernando Rasera. Universidade Federal de Uberlândia.

\section{Resumo}

A saúde sexual de pessoas com transtornos mentais severos e/ou persistentes não se mostra uma temática de grande investimento dos profissionais de saúde no Brasil, e raros são os estudos realizados com essa população. O objetivo deste estudo foi compreender os sentidos sobre sexualidade de pessoas usuárias de serviço de saúde mental negociados em oficinas de sexualidade. Foram realizadas 10 oficinas sobre sexualidade, com 43 usuários de um CAPS. A coleta de dados se deu por meio de áudio-gravação das oficinas e, posteriormente, sua transcrição, leitura atenta e análise por meio de categorias. Uma variedade de sentidos acerca da sexualidade pôde ser notada, relacionadas a: sentidos acerca da sexualidade; questões de gênero; informação, prevenção às IST/AIDS e direitos; e medicação e controle da sexualidade no CAPS. A pesquisa destaca a necessidade da discussão da sexualidade nos serviços de saúde mental, de forma a compreender, discutir e informar as pessoas usuárias.

Palavras-chave: sexualidade; saúde mental; CAPS; oficinas.

\begin{abstract}
Sexuality and mental health: Constructing meanings among CAPS users. The sexual health of people with severe and/or persistent mental disorders has not been shown a thematic of great investment of the health professionals in Brazil, and rare are the studies done with this population. The aim of this study was to understand the meanings about sexuality of people using mental health services negotiated in sexuality workshops. There were 10 workshops about sexuality, with 43 CAPS users. Data collection was done through audio recording of the workshops and, later, their transcription, careful reading and analysis through categories. A variety of meanings about sexuality could be noted, related to: senses about sexuality; Gender issues; Information, STI/AIDS prevention and rights; and medication and sexuality control in CAPS. The research highlights the need to discuss sexuality in mental health services, in order to understand, discuss and inform the users.
\end{abstract}

Keywords: sexuality; mental health; CAPS; workshops.

\section{Resumen}

Sexualid y salud mental: Construyendo sentidos entre usuarios de un CAPS. La salud sexual de las personas con trastornos mentales severos y/o persistentes no se ha demostrado una temática de gran inversión de los profesionales de la salud en Brasil, y son raros los estudios realizados con esta población. El objetivo de este estudio fue comprender los sentidos sobre la sexualidad de las personas que utilizan servicios de salud mental negociados en talleres de sexualidad. Hubo 10 talleres sobre sexualidad, con 43 usuarios de CAPS. La recolección de datos se realizó a través de la grabación de los talleres y, posteriormente, su transcripción, lectura cuidadosa y análisis por categorías. Se puede notar una variedad de significados acerca de la sexualidad, relacionados con: sentidos acerca de la sexualidad; Cuestiones de género; Información, prevención y derechos de las ITS/SIDA; y la medicación y el control de la sexualidad en CAPS. La investigación destaca la necesidad de discutir la sexualidad en los servicios de salud mental, con el fin de entender, discutir e informar a los usuarios.

Palavras clave: sexualidad; salud mental; CAPS; talleres. 
Apesar da escassez de práticas institucionais cotidianas relacionadas com a sexualidade no âmbito da saúde mental, na literatura brasileira é possível encontrar importantes sinais de preocupação na área representados pela publicação de guias sobre sexualidade e IST/AIDS voltados para profissionais e equipes de saúde (Mann, Oliveira, \& Oliveira, 2002; Ministério da Saúde, 2012), bem como aqueles voltados à identificação das vulnerabilidades das pessoas usuárias de serviços de saúde mental (Ministério da Saúde, 2008), os quais consideram que as pessoas com transtorno mental estão sujeitas a um maior risco de diversas condições adversas de saúde, como a exposição a ISTs.

$\mathrm{Na}$ literatura, os conceitos de sexualidade e transtorno mental assumem diferentes significados ao longo do tempo (Giugliano, 2004; Pinto, Mann, Wainberg, Mattos, \& Oliveira, 2007). Estudos atuais sobre a sexualidade das pessoas com trajetórias psiquiátricas estão preocupados com a disfunção sexual, implicações do uso da medicação na vivência da sexualidade, queixas relacionadas ao tipo de diagnóstico e atitudes dos profissionais em relação a elas.

Drake e Pathé (2004) estudaram a questão do possível comportamento sexual ofensivo de pessoas com diagnóstico de esquizofrenia e propuseram que, em apenas uma parte dos casos, tal comportamento se refere ao diagnóstico atribuído, posto que a outra parte pode se justificar por transtornos prévios ou apenas se afigurar como uma manifestação de um comportamento antissocial mais amplo. Por outro lado, McCann e DipThorn (2000) e Dimen (2001) afirmaram que as pessoas com diagnóstico de esquizofrenia podem viver sua sexualidade plenamente, porém, o preconceito, discriminação, opressão e atitudes negativas em relação a elas podem afetar muito sua autoestima. Vale notar a contribuição de Volman e Landeen (2007) que identificaram que, embora o transtorno tenha afetado aspectos da vivência sexual dos participantes, tanto pelo tratamento medicamentoso quanto pelas barreiras psicossociais enfrentados, muitos deles desenvolveram e mantiveram relações íntimas significativas e construíram seus próprios sentidos e significações acerca da sexualidade.

Östman (2008), ao realizar entrevistas tanto com pessoas internadas em hospital psiquiátrico quanto com seus parceiros, afirmou que os fatores que influenciam a vivência da sexualidade de pessoas diagnosticadas com transtornos mentais graves têm sido pouco estudados. Em outro estudo, Östman e Björkman (2013) descreveram que as pessoas com transtornos mentais e os seus parceiros têm um sentimento de abandono e descaso, por parte dos tratamentos psiquiátricos, e mostram insatisfação com os métodos de intervenção que não contam com a participação efetiva desses parceiros. Além disso, as pessoas entrevistadas também mostraram insatisfação com a quantidade e a clareza de informações que recebiam sobre o tratamento, principalmente em relação aos efeitos dos medicamentos. Falta de informações essa que pode resultar na exposição das pessoas às ISTs/AIDS.

Por sua vez, Collins (2001), além de destacar uma carência de dados sobre a temática, encontrou ambivalências na opinião dos profissionais de saúde mental que participaram de sua pesquisa sobre a sexualidade de mulheres diagnosticadas com transtornos mentais, que ora afirmavam que as vivências sexuais dessas mulheres eram influenciadas pelo diagnóstico, ora não sabiam informar sobre a sexualidade delas. O fato, para a autora, poderia constituir uma barreira a ações de prevenção ao HIV com essa população.

Por outro lado, Wainberg et al. (2008), em estudo sobre o comportamento de risco para o HIV com 98 usuários de ambulatório de saúde mental no Rio de Janeiro, mencionaram que cerca de $45 \%$ das pessoas participantes do estudo informaram não utilizar métodos de prevenção durante o ato sexual. Wainberg et al. (2008) destacam ainda que, no Brasil, há a necessidade de programas de prevenção ao HIV, principalmente dentro de serviços de atenção à saúde mental. Em outro estudo brasileiro, sobre a prática do sexo desprotegido entre uma amostra de 2237 pessoas com transtornos mentais e fatores associados, Guimarães, McKinnon, Campos, Melo e Wainberg (2010) consideraram que essa população apresenta muitos comportamentos de risco para o HIV, que seriam a prática do sexo desprotegido e seus fatores associados como, por exemplo, o uso de álcool e/ou outras drogas.

A maioria dos estudos tem suas linhas voltadas para a questão do transtorno, da disfunção, da anormalidade, tais como os que tratam dos fatores que envolvem os efeitos colaterais dos medicamentos, como os de Haefliger e Bonsack (2006), Higgins, Nash e Linch (2010), e Cohen et al. (2007). Sabe-se da importância dos estudos envolvendo todos os aspectos da sexualidade das pessoas com diagnóstico de transtornos mentais, inclusive os efeitos colaterais dos medicamentos. Porém, neste sentido, cabe citar o trabalho de Schmidt et al. (2012), que destacam a necessidade urgente de ensaios clínicos bem conduzidos, cegos 
e com escolha aleatória dos participantes, visando analisar os efeitos da redução da dosagem da medicação, interrupções no uso e terapias alternativas sobre pessoas com disfunções sexuais induzidas por antipsicóticos. Assim, será possível analisar contextualmente a influência da medicação para cada pessoa e não correr o risco de generalizar. Prender-se apenas às questões psiquiátricas e esquecer-se das sociais pode ser um grave erro, prejudicando, inclusive, a pessoa em seu território.

Avalia-se também que as diversas temáticas estudadas no âmbito da sexualidade em saúde mental apresentam diferentes visões, tanto por parte dos profissionais, como pelas pessoas usuárias dos serviços de saúde. Essas diferenças, contudo, estão associadas à forma e às vulnerabilidades sofridas por essa população. Em comum, além de chamarem atenção para sua importância, todos avaliam que as vivências sexuais dessas pessoas são historicamente construídas sob estigma, preconceito e negligências de direitos. Além disso, apesar de alguns estudos afirmarem maior frequência de comportamentos de risco dessa população, outros indicam não haver essa relação, relatando que podem viver sua vida sexual plenamente. Relatar que as pessoas diagnosticadas com transtornos mentais têm comportamento de risco devido apenas a sua condição é uma lógica normativa, generalista e perigosa, que contribui para o aumento do estigma entre familiares e profissionais.

Vê-se que as questões envolvendo sexualidade, práticas, prevenção e uso de medicamentos devem ser tratados não como mais um sintoma, mas dentro do contexto social, questionando as noções essencialistas e normatizadoras. Assim, tendo em vista a importância e a complexidade da temática para a área da saúde mental, o objetivo desta pesquisa foi compreender os sentidos sobre sexualidade para pessoas usuárias de serviço de saúde mental negociados em oficinas de sexualidade.

\section{Método}

O estudo desenvolveu-se em uma perspectiva qualitativa, orientando-se por uma concepção construcionista social da produção do conhecimento, a qual, por meio de uma crítica a uma concepção de conhecimento como representação, redimensiona a relação sujeito-objeto, a natureza do real, e promove uma visão da ciência enquanto produção sócio-histórica (Rasera \& Japur, 2003).

Ele foi realizado em um Centro de Atenção Psicossocial I. A participação na pesquisa era livre para pessoas com mais de 18 anos, que somaram 43 usuários do serviço, sendo 29 mulheres e 14 homens. De acordo com informações contidas em seus prontuários, 21 pessoas eram solteiras, uma era divorciada, 11 eram casadas e 10 estavam em relação estável, sendo sua média de idade de 43 anos. O tempo médio de permanência no serviço, baseado na data de início de tratamento, era de 5,5 anos.

Todas as oficinas dessa pesquisa foram desenvolvidas e facilitadas pelo primeiro autor do estudo, a partir da proposta de jogos dramáticos (Yozo, 1995). Sua realização tanto buscou oportunizar a abertura de espaços de troca e diálogo com os usuários de um CAPS I, quanto servir de subsídio e modelo para que profissionais do serviço pudessem dar continuidade às atividades e ampliar a atenção à demanda envolvendo a sexualidade na área da saúde mental. As temáticas tratadas durante as oficinas foram: 1) sexualidade; 2) mitos, crendices e tabus sexuais; 3 ) identidade de gênero; 4) orientação sexual; 5) sexualidade e saúde mental; 6) direitos sexuais e reprodutivos; 7) IST/AIDS; 8) sexo seguro; 9) dificuldades na vivência da sexualidade dos usuários de saúde mental; e, por fim, 10) a avaliação das oficinas. Foram realizadas semanalmente, com duração média de $1 \mathrm{~h}$ e $20 \mathrm{~m}$.

O número de participantes variou entre cinco a 17 pessoas por oficina. A participação de cada pessoa também foi bastante diversa, sendo que apenas duas pessoas participaram de todas as oficinas. Assim, dada a variação da quantidade de participantes em cada oficina, cada uma delas apresentou diferentes dinâmicas de interação, climas afetivos e ritmos.

Para a coleta de dados da pesquisa, as 10 oficinas foram gravadas em áudio e transcritas. Ao término de cada encontro, o facilitador elaborava um diário de campo, com as impressões sobre a oficina e a participação dos presentes; também eram registrados neste documento os bastidores de conversas com profissionais e pessoas presentes no serviço.

Posteriormente, realizou-se uma análise extensiva das transcrições das oficinas e definiram-se os passos para a análise das oficinas baseados em Spink (2010), os quais foram: 1) Transcrição das oficinas; 2) Leitura atenta das transcrições; 3) Construção de temáticas para discussão: a partir da leitura do material 
transcrito atentou-se aos diálogos entre os participantes buscando uma reflexão crítica do material, das relações estabelecidas entre facilitador e participantes e a identificação dos sentidos produzidos; 4) Reflexão e discussão dos resultados com a literatura produzida na área.

Este estudo foi encaminhado para análise e aprovado pelo Comitê de Ética em Pesquisa com Seres Humanos local. Todos os nomes utilizados são fictícios, com exceção do nome do facilitador, um dos autores do artigo.

\section{Resultados e discussão}

Com o intuito de compreender os sentidos sobre sexualidade negociados por pessoas usuárias de um serviço de saúde mental, identificaram-se as seguintes categorias: a) sentidos acerca da sexualidade; b) questões de gênero; c) informação, prevenção às IST/ AIDS e direitos; e d) medicação e controle da sexualidade no CAPS. Cada categoria foi criada com o objetivo de que fossem abordadas todas as principais questões surgidas ao longo do percurso da realização das oficinas. Em seguida, serão apresentadas cada uma das categorias e as falas que as representam.

\section{Sentidos acerca da Sexualidade: Diversidade e Desafios}

Foram observadas falas que se referem às vivências da sexualidade das pessoas usuárias do CAPS, as quais contêm formas de descrever a sexualidade, os prazeres sexuais e seus riscos, assim como os problemas e as possíveis soluções encontradas por elas na expressão dessas vivências.

No que se refere à diversidade de sentidos, em atividades presentes na primeira e oitava oficina, aponta-se a relação da sexualidade e do sexo com afeto, respeito, saúde e liberdade:

Vitória: Oh, eu acho assim, primeiro, respeito, né? (...)

Teodoro: (...) sexualidade pra mim, né, sexualidade não é o sexo propriamente dito, né? Acho que o sexo vai ser o ponto final. Pra mim sexualidade, o que me veio na minha cabeça é atração física aí que vai surgindo, que surge mutuamente ai entre sexos opostos ou entre iguais aí. (Oficina 1)

Vitor: Qual foi a primeira palavra ou frase que veio a sua cabeça quando eu falei "sexo"?

Vivian: A primeira palavra que veio na minha cabeça, veio uma frase, sexo é saúde, né.(...)
Leila: Sexo é uma coisa que todos necessitam, só que também precisa de prevenção.(...)

Daniel: liberdade. (...)

Danúbia: Sexo pra mim é dizer não. (...)

Agenor: Sexo é uma coisa que faz o amor, é o sexo. (Oficina 8)

Também na oitava oficina foi construída uma "árvore dos prazeres", na qual os participantes desenvolveram sua copa enumerando maneiras de se obter prazer sexual e, ao seu redor, os riscos trazidos pelos prazeres citados. As maneiras apontadas mostraram diferentes opiniões dos participantes, envolvendo: 'beijo', 'beijos no pescoço', 'carinho', 'tocar nos seios', 'carícias', 'cheiro', 'fogo', 'saúde', 'liberdade', 'posições', 'massagem', 'visita', 'toque', 'amor', 'aperto de mão', 'companhia', até questões relacionadas com o ato sexual em si.

Pela atividade, foi possível destacar a diversidade de falas envolvendo palavras com menções aos prazeres sexuais e, em relação a estas, as poucas palavras referentes aos riscos - 'dor', 'sofrimento', 'preocupação', 'sexo inseguro', 'coceira', 'bactérias', 'sífilis', 'gonorréia', 'crista de galo', 'fungo', 'infecções' - que estes trazem quando experienciados. Um termo citado chama atenção e pode ser um indício deste movimento, a "falta de informação" existente, para os usuários de serviços de saúde mental, sobre esses riscos.

A diversidade de sentidos sobre a sexualidade encontrada no estudo reafirma aqueles apresentados pela população brasileira tal como descrito na literatura nacional que apontam a sexualidade como forma de manter um relacionamento, tendo implicações para a qualidade de vida (Cunha, Spyrides, \& Souza, 2011; Paiva, Aranha, \& Bastos 2008). Especificamente sobre os sentidos usados por usuários dos serviços de saúde mental, Pinto et al. (2007) também encontraram uma diversidade de conceitos, crenças e atitudes em relação à sexualidade, como ocorrido nas oficinas 1 e 8 , em que os comentários expressam múltiplos sentidos a respeito do termo. Os autores destacam que pouco tem se discutido sobre o tema e mencionam a necessidade da participação dessas pessoas na criação de intervenções que visem, principalmente, a prevenção de ISTs.

Expostos os sentidos presentes nas conversas entre os participantes sobre sexualidade e prazeres sexuais, também cabe citar falas que expressam dificuldades na vivência da sexualidade.

Olívia: Falta de carinho, falta de atenção. Danúbia: Desgosto. 
Olívia: Tristeza.

Cássia: Dificuldade de sair para arrumar um namorado.

Ruan: Dificuldade de ter orgasmo. (Oficina 9)

Danúbia: Ele já pôs, é dificuldade de ter relação.

Rafael: Em ter relação.

(...)

Danúbia: Cê não tem só isso não! Você tem mais! Tristeza, mágoa, falta de carinho, amor, dificuldade psicológica, eu pus o meu...

Ruan: O senhor aí de verde. O Sr. tem dificuldade pra paquerar, pra...

Solivan: Ter amor a si próprio. (Oficina 9)

Sobre o tema, Barbosa, Souza e Freitas (2015) observaram baixa autoestima e sentimento de inferioridade relacionados ao preconceito social, por conta de serem usuários de serviços de saúde mental, como visto no trecho supracitado. Os dados representam um contexto de importantes dificuldades econômicas e sociais.

Muitas dificuldades também foram citadas durante os encontros. São preocupantes as questões levantadas, por exemplo, a falta de informações sobre os riscos que acompanham a vivência da sexualidade, atrelados aos interesses no controle das pessoas usuários de serviços de saúde mental pelo poder médico e gestores, que contribuem para o aumento do estigma social que, por sua vez, leva ao desamparo familiar e sentimento de inferioridade. Assim, se identifica a formação de um círculo vicioso que deve ser levado a sério e sofrer intervenções pautadas nas políticas públicas de saúde mental, para ser quebrado.

\section{Questões de Gênero: Diferença e Violência}

Durante as oficinas, várias pessoas traziam experiências a respeito dos relacionamentos afetivos que estabeleceram ao longo da vida, nos quais diversas questões envolvendo as relações de gênero estiveram presentes, tais como: machismo e opressão da mulher; papéis masculinos e femininos; cônjuge ideal; modos de relação conjugal; violência física e violência psicológica contra a mulher.

Vitória: Você pode ver até hoje a mulher é independente, mas tem homem que gosta que a mulher seja submissa pra eles. E até nessa parte da sexualidade.

Vitor: E qual a vantagem pra eles de a mulher ser submissa?

Vitória: Ela vai estar ali debaixo das asas deles, né, elas fazem o que eles querem. (Oficina 2)
Danúbia: Não, eu acho mais desvantagem porque, cê vê, eu tenho um casamento de 27 anos e são sofridos esses 27 anos que to vivendo com ele. Já tomei tapa, levei murro, já quebrou meu dente, já me humilhou, já me pisou. Eu acho, assim, muita desvantagem. Hoje eu sou uma pessoa frustrada com tudo isso. Homem, pra mim, acabou, só se fosse outro... (Oficina 3)

Há falas que expressam os sentidos atribuídos ao masculino e ao feminino na sociedade. As descrições reforçam não só o aspecto da submissão, mas também da dependência da mulher em relação ao homem. Constata-se isso nas falas de Vitória, que expressa a conquista da independência financeira pela mulher, mas também a submissão e dependência construída na relação com o homem.

Percebe-se que as falas variam, são citadas desde questões relacionadas com a dificuldade da compreensão das pessoas acerca de suas demandas e no controle do corpo feminino:

Vitor: Daí quando você põe o tema de sexualidade então fica pior ainda?

Liza: Fica pior ainda.

Raquel: E se ocê arruma namorada, ele "uai, cê tá é doida, cê vai lá?"

Selma: "Uai, cê é doente e agora cê já tá dando?", desse jeito minha irmã fala.

Vitor: Como se uma pessoa não pudesse viver a sexualidade dela, é isso?

Raquel: Não, se você é doido você não pode beijar, você não pode arrumar um namorado, você não pode fazer amor, com coisa que você não tem vontades, não tem desejo, não tem fantasia.

Vitor: Não pode se cuidar, né Raquel?

Danúbia: Não pode se cuidar, não pode passar pintura. Os outro vê e fala "uai, cê não é doido? Porque que tá se pintando?"

Olívia: Não pode pintar o cabelo.

Danúbia: Não. (Oficina 5)

Falas como de Liza, Raquel, Selma e Danúbia combinam as opressões de gênero e de "loucura", fazendo com que o "ser louco" seja diferente para as mulheres. Cabe citar também as falas de Olívia sobre estas questões de gênero, em que o homem que trabaIha fora não divide nenhuma função doméstica com a mulher. Santos (2009, p. 1181) afirma que as tentativas de incorporar o tema gênero na saúde mental, feitas pelo aparato médico psiquiátrico, trazem as mulheres associadas "as suas funções reprodutivas (gravidez, parto, puerpério, menopausa). Assim, trata-se de uma 
concepção reducionista e biologizante da saúde mental das mulheres". O autor menciona que o diagnóstico de transtornos psiquiátricos não impediu as mulheres de desempenhar as prescrições tradicionais de gênero: mãe; esposa; e demais tarefas domésticas. Prescrições estas também citadas durante a oficina 2, por Vitória, e por Olívia, na oficina 8.

Situações extremas de desrespeito e reforço de estigmas vividos pelos participantes também foram identificadas e, como podemos observar a seguir, há exemplos de situações claras de abuso durante a vivência da sexualidade de pessoas participantes das oficinas, e os padrões se intensificam em atos de maior violência. Em suma, mais exemplos de violência psicológica e física:

Edna: A violência sempre pesa mais pro lado da mulher, né? (Oficina 8)

Vitor: E sexualidade é só isso? Ficar junto é só isso? Raquel: Não é só isso, mas eles não entendem. Se não dá eles ficam falando "cê não me ama", "cê não me ama mais", "cê tá dando pra outro"...

Olívia: É desse jeito.

Raquel: Aí começa os tormento "vagabunda!"

Olívia: Eles batem na gente, né?

Vitor: Entendi, entendi. (Oficina 5)

Barbosa, Giami e Freitas (2015), buscando compreender as formas de viver e pensar a respeito da sexualidade das pessoas com transtornos mentais, destacaram a passividade e subordinação dessas mulheres em relação aos homens. Além disso, as autoras mencionam que a sexualidade das entrevistadas era vivida com limites e repressão, como exposto por Edna na oficina 8, por Danúbia, nas oficinas 8 e 5 e por Olívia, Raquel e Selma durante a oficina 5. Cabe citar o trabaIho de Zanello, Fiuza e Costa (2015, p. 241), que entrevistaram pessoas usuárias de um CAPS e observaram "uma conformidade com os valores de nossa sociedade patriarcal que subjuga o corpo de mulher ao status de objeto do homem".

Percebem-se possíveis configurações culturais de gênero expostas, que impedem a satisfação sexual e configuram violações dos direitos humanos dessas populações ampliadas pela condição de viver com o diagnóstico de transtornos mentais (Barbosa, Giami et al., 2015). O uso da mulher como objeto para obtenção de prazer sexual e sua exposição ao risco de infecção por ISTs foram mencionados durante as oficinas. Barbosa, Giami et al. (2015), estabelecendo a diferenciação entre roteiros sexuais de homens e mulheres, afirma que há a necessidade social constante de os primeiros buscarem o sexo como fonte de prazer e forma de confirmar sua masculinidade, já para as mulheres a relação sexual não é vista como prazerosa, mas como obrigação em relação a seus parceiros.

É preciso considerar duas importantes questões. Primeira, a discriminação das mulheres é recorrente, elas têm sempre um esforço enorme para superá-la em relação aos papéis de gênero impostos pela sociedade, inclusos aí o acesso aos serviços de saúde e a garantia de um espaço que as possibilite vivenciar suas sexualidades (Roeder, 2014). Segunda, soma-se a ela o transtorno mental e o rótulo social imposto sobre a pessoa que faz tratamento para "doenças da cabeça". Portanto, este estigma, a repressão, a passividade e a subordinação tendem a se agravar quando unimos os termos "mulheres que fazem tratamento para transtornos mentais graves" (Roeder, 2014; Santos, 2009; Zanello et al., 2015).

Vê-se que, além do adoecimento psíquico para o qual buscam tratamento no CAPS, essas pessoas trazem diversas demandas, extremamente importantes e que merecem atenção especializada dos profissionais do serviço. Assim, as questões de gênero são importantes fatores para o planejamento de intervenções com este público, de modo que os serviços de atenção psicossocial não reproduzam os estereótipos que possam contribuir para o agravamento do quadro de seus usuários, nem rotulem quaisquer comportamentos que considerem desviante da norma estabelecida.

\section{Informação, Prevenção às IST/AIDS e Direitos}

Foi possível notar que o reconhecimento dos riscos entre usuários pode estar relacionado com a quantidade e qualidade da informação que recebem. O uso de preservativos por alguns parece comprometido por conta do abuso de drogas (Barbosa \& Freitas, 2014) e por acharem que o fato causaria diminuição do prazer, tabu bastante recorrente entre os homens (Paiva, 1992). Sobre a questão do autocuidado e prevenção, Barbosa e Freitas (2014) mencionam o confronto entre risco, prazer e conjugabilidade. As autoras destacam o fato de os usuários pouco conhecerem sobre as ISTs e, apesar de haver um reconhecimento do risco envolvido, pouco utilizarem os preservativos.

Nas falas que seguem, por exemplo, vemos também a caracterização das mulheres como objetos em seus relacionamentos conjugais, com situações 
preocupantes contendo empecilhos para prevenção das ISTs através do uso de preservativo.

Edna: Então, mas é assim, conforme cê tiver fazendo o tratamento, durante o tratamento, tem que usar camisinha.

Olívia: Ah, nós nunca pôs.

Selma: Só que meu ex marido nunca colocou nada.

Olívia: Nem durante o tratamento?

Selma: Não.

Danúbia: Não pode. Não, durante o tratamento cê não pode ter relação, né. (...) Cê tá fazendo tratamento, tá tomando antibiótico, usando pomada, então você não pode ter relação durante aquele tempo, até retornar ele. (Oficina 8)

As falas anteriores retratam hierarquias de valor entre masculinidade e feminilidade, contra as quais muito tem se lutado. Assim, essas hierarquias acabam gerando violência, como Danúbia negociando o uso de preservativo com o cônjuge, mas cedendo e se expondo à ISTs forçadamente.

Notam-se também algumas implicações, que podem estar relacionadas tanto com a falta de informações sobre as ISTs e formas de cuidado em relação ao sexo desprotegido para esta população, passando pela falta de informações sobre os direitos sexuais e reprodutivos, quanto com o que também abrange grande parte da população adulta, a sensibilização através da discussão sobre os aspectos da sexualidade.

Representando uma lógica maior de ausência de métodos eficientes de informar nos serviços de saúde mental, esses usuários desconheciam quaisquer ISTs e, sendo tão grave quanto, em atividade da sexta oficina, demonstraram conhecimento superficial sobre seus direitos sexuais e reprodutivos. No fim, muitos disseram que não sabiam que direitos tinham e, além disso, que esses direitos não Ihes eram informados nos serviços que frequentam:

Vitor: Vamos lá gente, ó "Como parte dos direitos humanos, para que eu possa viver a minha vida sexual e reprodutiva com liberdade, prazer $e$ saúde, eu tenho direito de...", eu tenho direito de quê?

Lúcia: Ser feliz!

Andressa: Ter direitos igual os outros, né?

Vitor: Mas que direitos?

Andressa: Todos os direitos. (...)

Olívia: Direito de ser livre igual um passarinho.(...)

Olívia: E ser respeitado, pode ser um desses dois.

Jéssica: Ser respeitado. (...)

Vilma: É, vixi. Ter paz (...)
Danúbia: Direito de não fazer. (Oficina 6)

Apesar de se reconhecerem como portadores de direitos diversos, as pessoas que participaram da atividade específica para este fim não souberam caracterizá-los e nem o que fazer quando um desses direitos Ihes é usurpado. Por outro lado, podemos observar diferentes sentidos dados à relação entre os direitos e a sexualidade. Lúcia vê a felicidade como um importante direito. Andressa aponta sua condição de portadora de direitos. Olívia expressa a importância que enxerga na liberdade e no respeito, assim como Jéssica. Vilma cita a paz, frequentemente ligada ao oposto da violência nos discursos presentes na atualidade. Danúbia, que frequentemente citava os abusos e violências do companheiro, expressou seu direito de dizer não. Enfatizam-se aqui as implicações que essa carência de informações gera tanto para o serviço, quanto para seus usuários que, sem esse tipo de conhecimento, ficam sujeitos a diversas violações e violências.

Além disso, sobre a questão dos direitos sexuais e reprodutivos, Ávila (2003) menciona a importância da influência que o saber e o poder médicos têm nas definições tradicionais de regras que servem para reprimir e controlar as vivências sexuais. O saber médico, somado à visão excludente dos gestores e profissionais perante os serviços de saúde mental e as pessoas usuárias, mais o estigma social, são determinantes para a falta de informações que chegam até essas pessoas.

\section{Medicação e Controle da Sexualidade no CAPS}

Entre as terapêuticas existentes nos CAPS, há o tratamento farmacológico e, por consequência, há os efeitos colaterais da ingestão dos medicamentos. Dentre os efeitos existentes, revelou-se, nas falas das pessoas participantes das oficinas, diminuição ou aumento da libido, desânimo, ausência de prazer, entre outros. A fim de ilustrar melhor esses efeitos, seguem as falas:

Raquel: (Vamos supor), foi eu que comecei com essa conversa, sabe por quê? Porque eu ficava conversando com minhas amigas, com o tratamento que a gente faz, (como se diz, assim), a gente perde a vontade, não tem prazer e, muita gente tem vergonha de questionar isso, você entendeu? É por isso que eu dizia pra você pegar e estudar um pouquinho, pra ver. Porque, com os remédios, o passar do tempo, tem gente que fica uma geladeira. (...)

Vitor: Perde o tesão, é isso? 
Raquel: Isso, perde o tesão, você não tem tesão, cê entendeu? Você não tem vontade de ir lá, beijar, abraçar, agarrar.

Agenor: Dar carinho...

Raquel: Isso! Perde o casamento, perde a mulher, perde várias outras coisas, cê entendeu? A pessoa não tem vontade. Não é porque ela não quer, porque muitas vezes os maridos brigam com as muié, vai "você não quer, você não quer ficar comigo", e não é isso, é porque a mulher não tem desejo, não tem vontade. (Oficina 1)

Os trechos marcam os efeitos adversos dos medicamentos, que contribuem para diminuição das motivações e sensações de prazer em suas vivências na sexualidade. Na literatura, é possível encontrar que a atenção, principalmente médica, às questões de sexualidade às pessoas usuárias de serviços de saúde mental é falha (Dallon \& Abraham, 2009; Rele \& Wylie, 2007; Voermans, Van, Peen, \& Hengeveld, 2012), além de destacar que as informações repassadas às pessoas sobre os efeitos adversos da medicação são escassas (Rele \& Wylie, 2007).

Haefliger e Bonsack (2006) e Higgins et al. (2010) propõem a redução de doses dos medicamentos ou até mesmo a mudança para substâncias alternativas, porém, afirmam que as pessoas da área psiquiátrica ficam receosas com esta possibilidade pelo medo de novas substâncias exacerbarem os sintomas psiquiátricos.

A respeito dos efeitos do uso de psicotrópicos na sexualidade dos usuários e com o propósito de investigar outras relações acerca das vivências dessas pessoas, destacam-se outros contextos nos trechos a seguir:

Helena: Eu até hoje \{Vitor: Vamos ouvir a Helena, calma gente\}, pra mim a sexualidade faz parte da minha vida, do meu dia a dia, é uma coisa que eu preciso pra sobreviver, porque sem isso eu não vou sobreviver mesmo...

Amanda: Não! ((risos))

Helena: $E$, só que esses remédio mexe com os nervo da gente \{Raquel: Muito\}, às vezes da uns relaxante pros nervo, né? Mas com companheirismo, um pouquinho de carinho, tudo dá certo. (Oficina 1)

Observa-se que aspectos associados às suas relações conjugais, tais como o carinho, a atenção e o afeto, são bastante relevantes para obtenção dessas vivências de satisfação, o que destaca a necessidade de terapêuticas alternativas com maior foco em vínculos sociais e menos nos medicamentos. Nota-se a necessidade de se ter uma visão integral da pessoa usuária de um serviço de saúde mental, acolhendo assim, todas as suas demandas.

As implicações da relação do uso dos medicamentos com as experiências de prazer das pessoas podem reverberar na atenção que os profissionais e o serviço dispõem em relação à sexualidade das pessoas usuárias. As intervenções medicamentosas, por vezes, constituem práticas que remetem ao controle da sexualidade dos usuários, como apontam Raquel e Teodoro:

Vitor: O que eu quero saber é isso, é o tema de hoje, assim, vida pessoal, sexualidade. (...)

Raquel: Aí eu fui falar com ela sobre sensualidade, sabe o que ela falou?

Vitor: É isso que eu queria saber.

Raquel: Então, eu fui falar com ela "Doutora, eu tomo uns remédio e não tenho vontade, não tenho tesão". Ela falou assim "É, com tanto medicamento desse você quer sentir o quê?". (Oficina 5)

Teodoro: (...)Aí eu trouxe o remédio aqui e ela falou que tinha me dado o remédio que era justamente pra isso, que eu não precisava de ter mulher agora. Aí eu fui ali também, não tem nem preservativo e nem nada ali. Não é por nada não, cêis me desculpa aí. ((caminha para sair do grupo)). (Oficina 1)

Vale notar as falas de Raquel e Teodoro que dizem respeito ao que parece ser uma forma de castração química, na qual os medicamentos são utilizados pelos profissionais justamente para inibir as vivências sexuais das pessoas usuárias. Pode-se entender aqui que há uma má qualificação desses profissionais no acolhimento das questões que envolvem a sexualidade das pessoas. Por conseguinte, práticas que poderiam ser acolhedoras se tornam negadas por esses profissionais, deixando as pessoas sem atendimento para os problemas apresentados.

Além disso, uma problemática tão grave quanto a negação, é a negligência de alguns profissionais. As falas dos participantes envolvem situações preocupantes de relações conjugais, violência familiar, ideações suicidas e castração química, que parecem ser mal administradas ou ignoradas. Entende-se, portanto, que há a necessidade de supervisão institucional e profissional no cotidiano do CAPS.

\section{Considerações finais}

Afinal, o que os sentidos pesquisados permitem afirmar? Que a sexualidade das pessoas participantes é 
bastante atravessada por sua vivência como usuários de um CAPS, porém, ao contrário do que aponta a literatura, isto não advém unicamente do transtorno que Ihes é atribuído pelo aparato médico psiquiátrico, mas do estigma e preconceito social reproduzidos pelos discursos dos gestores, profissionais e o restante da sociedade.

A impossibilidade de acolhimento da sexualidade dos usuários pelos serviços reafirma experiências de violação no exercício de direitos. As práticas relatadas pelas pessoas participantes das oficinas remetem aos resquícios do modo manicomial de atenção à saúde, no qual não há traço de respeito à autonomia ou acolhimento integral das pessoas. Sendo este modelo alvo de constantes lutas por sua mudança, repetido em um serviço criado para ser seu substituto, com novas terapêuticas e formas de atenção, são claros os sinais de retrocesso e de pouco compromisso dos gestores e profissionais com a luta antimanicomial, e com a saúde integral das pessoas que ali frequentam. Os dados coletados na pesquisa demonstram formas de negligência relevantes dentro de um serviço para atendimento de pessoas diagnosticadas com transtornos mentais graves e/ou persistentes, as quais necessitam de cuidado e acolhimento. As falas das pessoas participantes também demonstraram que os profissionais deste serviço pouco refletem sobre suas práticas e que parece não haver integração da equipe ou discussão de casos, nem reuniões ou assembleias, formas de participação social fomentadas nos CAPS. Este despreparo diante das práticas psicossociais pode estar ligado à formação dos profissionais ainda focada no modelo biomédico psiquiátrico, centrado unicamente em um transtorno, não nas pessoas ou na comunidade. Isso destaca a existência de uma lógica que pode estar presente também em outros serviços e traz à tona a necessidade constante de avaliação dessas práticas para que sejam condizentes com o modelo psicossocial: territorial, comunitário, acolhedor e humanizado. Assim, o aprimoramento da qualidade dos serviços depende de práticas de educação permanente, pois, muitas vezes, a formação oferecida nos cursos de graduação ainda não contempla de forma efetiva o que é proposto pela Reforma Psiquiátrica.

Será que a sexualidade dessas pessoas é diferente? A desinformação sobre os direitos sexuais é generalizada na população brasileira. O estigma pode fazer toda a diferença no modo com que essas questões são tratadas, não em relação à patologia. Claro que é importante pensar as especificidades das pessoas, por isso se enfatiza aqui a necessidade de uma terapêutica concisa individual ou grupal. Contudo, para pensar essas singularidades não é necessário ter um viés puramente patológico.

Muitas questões levantadas caminharam para a necessidade de o usuário ser participante ativo das intervenções que visem seu cuidado, tanto ao diagnóstico, quanto às questões relacionadas com sua sexualidade e saúde sexual, principalmente no que tange a prevenção das ISTs e HIV/AIDS e ao tratamento medicamentoso. Não é exagero reafirmar a necessidade de não enxergar sua sexualidade como sintoma, mas como fruto das relações que essas pessoas estabelecem ao longo de suas vidas. Portanto, é importante refletir sobre os impactos cotidianos produzidos pelo discurso biomédico, do patriarcado e o religioso na vivência e no cuidado das questões de gênero e da sexualidade dos usuários do CAPS.

\section{Referências}

Ávila, M. B. (2003). Direitos sexuais e reprodutivos: desafios para as políticas de saúde. Cadernos de Saúde Pública, 19(1), S465-S469. doi: 10.1590/S0102-311X2003000800027

Barbosa, J. A. G., \& Freitas, M. I. F. (2014). Percepções de homens com transtornos mentais sobre risco e autocuidado face às infecções sexualmente transmissíveis. Saúde \& Sociedade, 23(2), 523-535. doi: 10.1590/S0104-12902014000200013

Barbosa, J. A. G., Giami, A., \& Freitas, M. I. F. (2015). Gender and sexuality of people with mental disorders in Brazil. Sexualidad, Salud y Sociedad, 19, 67-83. doi: 10.1590/1984-6487.sess.2015.10.06.a

Barbosa, J. A. G., Souza, M. C. M. R., \& Freitas, M. I. F.(2015). A abordagem da sexualidade como aspecto essencial da atenção integral de pessoas com transtornos mentais. Ciência \& Saúde Coletiva, 20(7), 2165-2172. doi: 10.1590/1413-81232015207.01792014

Cohen, S., Kühn, K. U., Bender, S., Erfurth, A., Gastpar, A., Murafi, A., ... Huber, T. J. (2007). Sexual impairment in psychiatric inpatients: Focus on depression. Pharmacopsychiatry, 40(2), 58-63. doi: 10.1055/s-2007-970143

Collins, P.Y. (2001). Dual taboos: Sexuality and women with severe mental illness in south africa. Perceptions of mental health care providers. AIDS and Behavior, 5(2), 151-161. doi: 10.1023/A:1011331028450

Cunha, M. K. M., Spyrides, M. H. C., \& Sousa, M. B. C. (2011). Os significados de saúde na relação sexual para mulheres assistidas pelo SUS na cidade de Natal, Rio Grande do Norte, Brasil. Cadernos de Saúde Pública, 27(6), 1099-1110. doi: 10.1590/ S0102-311X2011000600007

Dallon, C., \& Abraham, C. (2009). Psychose et sexualité. Revue Médicale Suisse, 5, 635-637. Recuperado de https://www.revmed. ch/RMS/2009/RMS-195/Psychose-et-sexualite

Dimen, M. (2001). Perversion is us? Eight notes. Psychoanalytic Dialogues, 11(6), 825-860. doi: 10.1080/10481881109348647

Estudos de Psicologia, 23(3), julho a setembro de 2018, 306-316 
Drake, C. R., \& Pathé, M. (2004). Understanding sexual offending in schizophrenia. Criminal Behaviour and Mental Health, 14(2), 108-120. doi: $10.1002 / \mathrm{cbm} .576$

Giugliano, J. (2004). A sociohistorical perspective of sexual health: The clinician's role. Sexual Addiction \& Compulsivity, 11(1-2), 43-55. doi: $10.1080 / 10720160490458238$

Guimarães, M. D. C., McKinnon, K., Campos, L. N., Melo, A. P. S., \& Wainberg, M. (2010). HIV risk behavior of psychiatric patients with mental illness: A sample of Brazilian patients. Revista Brasileira de Psiquiatria, 32(4), 351-360. doi: 10.1590/S1516-44462010000400007

Haefliger, T., \& Bonsack, C. (2006). Antipsychotiques atypiques et dysfonction sexuelle: à propos de cinq cas associés à la rispéridone. L'Encéphale, 32(1), 97-105. doi: 10.1016/S0013-7006(06)76142-5

Higgins, A., Nash, M., \& Lunch, A. M. (2010). Antidepressant-associated sexual dysfunction: Impact, effects, and treatment. Drug, Health Care and Patient Safety, 2, 141-150. doi: 10.2147/DHPS.S7634

Mann, C. G., Oliveira, S. B., \& Oliveira, C. S. S. (2002). Guia para profissionais de saúde mental/sexualidade e DST/AIDS: discutindo o subjetivo de forma objetiva. Rio de Janeiro/RJ: Instituto Franco Basaglia.

McCann, E., \& DipThorn, R. M. N. (2000). The expression of sexuality in people with psychosis: Breaking the taboos. Journal of Advanced Nursing, 32(1), 132-138. doi: 10.1046/j.1365-2648.2000.01452.x

Ministério da Saúde (2008). Secretaria de Vigilância em Saúde. Programa Nacional de DST e AIDS. Prevenção e atenção às IST/AIDS na saúde mental no Brasil: análises, desafios e perspectivas. Brasília, DF: Ministério da Saúde.

Ministério da Saúde (2012). Secretaria de Vigilância em Saúde. Departamento de DST, AIDS e Hepatites Virais. Atenção em saúde mental nos serviços especializados em DST/AIDS. Brasília, DF: Ministério da Saúde.

Östman, M. (2008). Severe depression and relationships: The effect of mental illness on sexuality. Sexual and Relationship Therapy, 23(4), 355-363. doi: 10.1080/14681990802419266

Östman, M., \& Björkman, A. C. (2013). Schizophrenia and relationships: The effect of mental illness on sexuality. Clinical Schizophrenia and Related Psychoses, 7(1), 20-24. doi: 10.3371/CSRP.OSBJ.012513

Paiva, V. (1992). Em tempos de AIDS. São Paulo: Summus.

Paiva, V., Aranha, F., \& Bastos, F. I. (2008). Opiniões e atitudes em relação à sexualidade: pesquisa de âmbito nacional, Brasil, 2005. Revista de Saúde Pública, 42(supl. 1), 54-64. doi: 10.1590/ S0034-89102008000800008
Pinto, D. S., Mann, C. G., Wainberg, M., Mattos, P., \& Oliveira, S. B. (2007) Sexuality, vulnerability to HIV, and mental health: An ethnographic study of psychiatric institutions. Cadernos de Saúde Pública, 23(9), 2224-2233. doi: 10.1590/S0102-311X2007000900030

Rasera, E. F., \& Japur, M. (2003). Grupo de apoio aberto para pessoas portadoras de HIV: a construção da homogeneidade. Estudos de Psicologia, 8(1), 55-62. doi: 10.1590/S1413-294X2003000100007

Rele, K., \& Wylie, K. (2007). Management of psychosexual and relationship problems in general mental health services by psychiatry trainees. International Journal of Clinical Practice, 61(10), 1701-1704. doi: 10.1111/j.1742-1241.2007.01455.x

Roeder, M. A. (2014). Sexualidade da mulher nos serviços residenciais terapêuticos em saúde mental - um ensaio etnográfico sobre "fragmentos de uma sexualidade contida". In V. Zanello \& A. P. M Andrade (Orgs.), Saúde mental e gênero (pp. 147-172). Curitiba: Appris.

Santos, A. N.C.C. (2009). Articular saúde mental e relações de gênero: dar voz aos sujeitos silenciados. Ciência \& Saúde Coletiva, 14(4), 1177-1182. doi: 10.1590/S1413-81232009000400023

Schmidt, H. M., Hagen, M., Kriston, L., Soares-Weiser, K., Maayan, N., \& Berner, M. M. (2012). Management of sexual dysfunction due to antipsychotic drug therapy (review). The Cochrane Library, 11, 1-50. doi: 10.1002/14651858.CD003546.pub3

Spink, M. J. (2010). Ser fumante em um mundo anti tabaco: reflexões sobre riscos e exclusão social. Saúde e Sociedade, 19(3), 481-496. doi: 10.1590/S0104-12902010000300002

Voermans, J. M., Van, H. L., Peen, J., \& Hengeveld, M. W. (2012). Het bespreken van seksuele problemen door psychiaters en aiossen. Tijdschrift Voor Psychiatrie, 54(1), 9-16. Recuperado de http://www. tijdschriftvoorpsychiatrie.nl/assets/articles/TvP12-01-p9-16.pdf

Volman, L., \& Landeen, J. (2007). Uncovering the sexual self in people with schizophrenia. Journal of Psychiatric and Mental Health Nursing, 14, 411-417. doi: 10.1111/j.1365-2850.2007.01099.x

Wainberg, M. L., McKinnon, K., Elkington, K. S., Mattos, P. E., Mann, C. G., Pinto, D. S., ... Investigators of PRISSMA. (2008). HIV risk behaviors among outpatients with severe mental illness in Rio de Janeiro, Brazil. World Psychiatry, 7, 166-172. doi: 10.1002/j.20515545.2008.tb00190.x

Yozo, R. Y. K. (1995). 100 jogos para grupos: uma abordagem psicodramática para empresas, escolas e clínicas. São Paulo: Ágora.

Zanello, V., Fiuza, G., \& Costa, H. S. (2015). Saúde mental e gênero: facetas gendradas do sofrimento psíquico. Fractal: Revista de Psicologia, 27(3), 238-246. doi: 10.1590/1984-0292/1483 
Vitor Corrêa Detomini, Mestre em Psicologia pela Universidade Federal de Uberlândia (UFU), é Psicólogo na UBS III "Dr. Dermival Franceschi" - Centro de Saúde da Prefeitura da Estância Turística de Pereira Barreto/SP (PMPB). Endereço para correspondência: Rua Dermival Franceschi ${ }^{\circ} 1826$, centro, Pereira Barreto/SP, CEP 15370-000. Telefone: (18) 981143315

E-mail:vcdetomini@outlook.com

Emerson Fernando Rasera, Doutor em Psicologia pela Universidade de São Paulo (USP), Pós-doutorado em Comunicação pela University of New Hampshire, EUA, é Professor Associado IV pela Universidade Federal de Uberlândia (UFU).

E-mail: emersonrasera@gmail.com

Recebido em 15.Fev.17

Revisado em 18.Dez.18

Aceito em 06.Fev.19 